OPEN ACCESS

Edited by:

Jukka Husu,

University of Turku, Finland

Reviewed by:

Khalil Gholami,

University of Kurdistan, Iran

Tracy X. P. Zou

The University of Hong Kong,

Hong Kong

*Correspondence:

Joanna Goode

goodej@uoregon.edu

Specialty section: This article was submitted to

Teacher Education,

a section of the journal

Frontiers in Education

Received: 29 August 2019 Accepted: 24 December 2019

Published: 21 January 2020

Citation:

Goode J, Skorodinsky M, Hubbard J and Hook J (2020) Computer Science for Equity: Teacher Education, Agency, and Statewide Reform Front. Educ. 4:162 doi: 10.3389/feduc.2019.00162

\section{Computer Science for Equity: Teacher Education, Agency, and Statewide Reform}

\author{
Joanna Goode ${ }^{1 *}$, Max Skorodinsky ${ }^{1}$, Jill Hubbard ${ }^{2}$ and James Hook ${ }^{3}$ \\ ${ }^{1}$ Department of Education Studies, University of Oregon, Eugene, OR, United States, ${ }^{2}$ Department of Computer Science, \\ Oregon State University-Cascades, Bend, OR, United States, ${ }^{3}$ Department of Computer Science, Portland State University, \\ Portland, OR, United States
}

This paper reports on a statewide "Computer Science for All" initiative in Oregon that aims to democratize high school computer science and broaden participation in an academic subject that is one of the most segregated disciplines nationwide, in terms of both race and gender. With no statewide policies to support computing instruction, Oregon's legacy of computer science education has been marked by both low participation and by rates of underrepresented students falling well-below the already dismal national rates. The study outlined in this paper focuses on how teacher education can support educators in developing knowledge and agency, and impacting policies and practices that broaden participation in computing. In particular, this research seeks to understand two questions. First, how do teachers experience equity-focused professional development in preparation for teaching an introductory course in computer science? Second, this study queries, how do teachers understand their own agency in influencing policies and practices that broaden participation in their specific schools and classrooms? To answer these questions, this inquiry employed a mixed method approach, drawing from surveys, observations, and interview data of two cohorts of teachers who participated in the Exploring Computer Science professional development program. To show the variety of school contexts and situate computer science education in local and place-based policies and practices, three teacher case studies are presented that illustrate how individual teachers, in diverse geographic and demographic settings, are building inclusive computer science opportunities in their schools. The findings reveal that centering equity-focused teacher professional development supports teachers in formulating the confidence, knowledge and skills that lead to inclusive computer science instruction, computer science content, and equity-centered pedagogy. The findings also highlight how school reform in computer science requires not only technical and pedagogical supports and structures, but also a systemic rethinking and reworking of normative and political forces that are part of the fabric of schools. Based on these findings of teacher knowledge and agency, the paper concludes with a presentation of particular statewide policies and practices that are generative in broadening belief systems and expanding political capacity of computer science education to reach all students.

Keywords: computer science education, teacher education, education policy, case studies, equity 


\section{INTRODUCTION}

In early 2016, President Obama endorsed a decade of federal investment in broadening participation in secondary computer science education and lit a firestorm of new efforts aimed at providing computer science instruction for all students. Despite the federal directive for funding to contribute to this "Computer Science for All" initiative, the constitutional mandate in the United States gives authority to the states to set education policies and practices. While the recent wave of federal support to bring computing knowledge to all students is unprecedented, it is evident that reforming computer science education must be attended to at the state level.

The urgency of expanding computer science education in the United States has been endorsed and supported by a variety of organizations and interest groups. Industry leaders, concerned about the future health of the work-force pipeline and personal economic prosperity, suggest that public investment to support computer science in schools is necessary for the nation's (and individuals') economic health. Cybersecurity experts point to the need for a well-educated citizenry to ensure both personal privacy, and to fill public sector jobs in security which cannot be outsourced abroad. Academic groups highlight the benefits of a "computer science $+\mathrm{X}$ " approach-education about how computer science can inform scientific and humanistic endeavors across and within other scholarly disciplines. Additionally, K12 educators and teachers note that the ethos of creativity and collaboration that can be fostered through computer science instruction has a reinvigorating and empowering impact on teaching and learning in classrooms.

\section{Inequitable Opportunities to Learn Computer Science}

Despite the widespread enthusiasm for computer science education for all, it is significant and troubling that computer science suffers from the lowest participation of girls and students of color than any other STEM-related area. These participation patterns continue, and often increase, in higher education and in technology-related professions (U.S. Equal Employment Opportunity Commission, 2016; Zweban and Bizot, 2018). Given the high-status nature of computer science (Apple, 1978), and the tremendous levels of power and influence that lie with those who have stature in this field, computer science education reform must prioritize to address the complex ways that racial and gender inequities operate and are reproduced in this discipline.

Prior research in equity and computer science has illuminated how structural and belief systems collide to create obstacles for many students to learn computing in schools. For instance, an ethnographic study focused on computer science education, across three high schools varying in demographic composition, revealed how learning opportunities, such as course offerings and qualified teachers, differed dramatically both between and within schools (Goode, 2008; Margolis et al., 2017). Additionally, educator beliefs and practices, at the school and classroom level, profoundly impacted students' opportunities to learn computer science through student tracking and enacted pedagogy in the classroom. This collision of structural and belief system biases in computing education result in significant and persistent participation gaps in computer science courses by students of color and girls (Ashcraft et al., 2017; Scott et al., 2019).

Further, for students of color and low-income students, existing discrepancies in opportunities to learn computer science in school settings are accompanied and compounded by other long-standing educational inequities. Studies have documented how across subject-areas, secondary students in the United States experience staggering disparities in access to high-quality teachers (Darling-Hammond and Berry, 2006), high-quality academic curricular experiences (Lee et al., 1997), and culturally relevant pedagogy (Ladson-Billings, 1995).

\section{The Role of Teachers in Computer Science for All}

There has been an ongoing and significant investment in expanding and scaling computer science education as part of the "Computer Science for All" initiative across the United States. Although teacher professional development is frequently considered integral to these efforts, there is scarce research about the specific role of teachers in serving as change agents in broadening participation in computing at their school sites. Little is known about how teachers can support rigorous and inclusive computer science course offerings. Such knowledge is especially necessary in order to best support efforts to diversify high school computer science classrooms in a state with a decentralized, "local control" education system. This study seeks to study how teachers develop and enact agency in terms of equity in computer science education. In particular, this research seeks to understand how teachers experience the equity-focus of professional development in preparation for teaching a high school introductory course in computer science, and how these teachers understand their own capacity in bringing computer science to their specific schools and classrooms and to diverse groups of students. A key part of our investigation is studying how belief systems of educators and policymakers shift as computer science education discourse collectively shifts from "for some" to "for all."

Studying teacher agency in the context of educational reform involves an examination of the actions of individual educators within particular social contexts marked by a set of resources that are culturally, socially, and historically developed (Lasky, 2005). This sociocultural model of teacher agency is mediated by the interaction between the individual and the structures impacting teachers' capability to exercise power, particularly in reform contexts that bring new normative professional tools and expectations. Further, an ecological theory of teacher agency suggests that while teachers as actors have some sort of capacities, their ability to achieve agency relies on the interaction between these capacities and the ecological contingencies of the environment (Biesta and Tedder, 2007). One study of teacher-enacted curriculum reform that examined teacher agency from an ecological perspective found that teacher agency is largely about "repertoires for maneuverer," or the possibilities for different forms of action available for teachers in their particular temporal, material, and social context (Priestley et al., 2012). 
This study discovered that the beliefs, values, and attributes that individual teachers mobilize in particular settings are important characteristics of teacher agency. The recommendations from this research emphasized that educational curricular reforms should focus on designing policies that proactively consider teachers' preemptive and anticipated engagement with new educational designs.

\section{Computer Science for Oregon}

The study outlined in this paper is part of a larger initiative that supports cohorts of teachers in bringing computer science education to Oregon, a state with a decentralized school system. Through support from the National Science Foundation and collaborations with multiple state policymakers and educators, the "Computer Science for Oregon" initiative is expanding access to inclusive learning experiences, beginning with high school classrooms. At the core of the theory of change for this equityfocused project is teacher education. Teachers not only have the unique and central position to bring active and inclusive pedagogy to introductory courses for all students, but they also hold the capacity, expertise, and agency to illuminate how local and statewide policies and practices can support and sustain social justice approaches to computing education.

To situate the equity context of schools in this study, this paper first provides an historical examination of the legacy of computer science education in Oregon and how these efforts, in the past, have reached only a narrow segment of the student population. Next, we engage in a theoretical discussion of the multiple components of school reform that must be attended to in order to center race and gender equity at the core of computer science school reform. Then, we describe the "Computer Science for Oregon" initiative and the role of teacher education in supporting the statewide goal to democratize computer science education. To examine the efficacy of these reform efforts, we present three case studies to illustrate how teachers, in diverse geographic and demographic settings, are building inclusive computer science opportunities at their schools. Each of these case studies features the teacher's school site context, their particular problems of practice in teaching computer science to a wide diversity of students, and how they have experienced powerful moments of teaching and learning that support the inclusive spirit of "Computer Science for All." After presenting these particular cases, we will discuss how our findings can inform an applied theory of action for "Computer Science for All" statewide efforts focused on a cohesive model of social justice-focused educational reform.

\section{BACKGROUND OF COMPUTER SCIENCE EDUCATION IN OREGON}

To provide a comprehensive understanding of the current context of Oregon's computer science education opportunities, policies, and practices, we present an historical inquiry of how computing has been integrated in Oregon schools. Using public education datasets, College Board data, and archival state documents, we examined patterns of course participation by racial and gender demographics. We also investigated available historical plans and policies. We observe how key events, organizations, and enrollment data have set the stage for the "Computer Science for Oregon" shift toward a focus on a more widespread adoption of computer science education offerings, as well as, on the inclusion and engagement of a diverse student body in the computing field.

\section{Teacher Role and Course Availability}

Oregon has a long history teaching computer science in formal (in-school) and informal (out-of-school-time) settings. By 1962, Oregon high school teachers were teaching programming. In 1978 Mr. Robert Jaquiss, a computer teacher at North Salem High School, developed a proposal to achieve "computer literacy for all" (Bennett et al., 1980). That proposal shows problem solving and simulation integrated into the study of social science, chemistry, physics, business, biology, mathematics, and music, and identified separate courses of study for programming, computer science, and computer operations. The Oregon Computer Science Teachers Association (OCSTA) formed in 1987. It has thrived as a partnership between educators and industry to support computer science content in formal and informal settings. Despite this long-standing niche of proponents for computer science education, no district in the state has yet designated computer science as a graduation requirement. Because computer science has historically been on the periphery of the school curriculum, Oregon, like many states, does not have a certification available in the discipline for teachers. In order to teach computer science at the secondary level, teachers who are already certified and hold endorsements in other subjects, often are asked or choose to obtain professional learning in the subject in short-term workshops (often only available during summer break months). Additionally, many computing teachers are former technology professionals who have entered the teaching profession as part of a CareerTechnical Education program, circumventing traditional teacher education preparation programs that include teaching methods courses. This uneven pipeline of computing teacher preparation has resulted in a dearth of educators prepared to offer computer science in Oregon high schools. Additionally, there is wide variability of the types of computer science courses that are available across the state. Of the 325 Oregon high schools reporting data to the Oregon Department of Education for the academic year ending 2015, 232 listed some computing or technology course, 66 listed a regular offering coded as programming, and 14 offered Advanced Placement or International Baccalaureate computer science classes.

\section{Course-Taking}

With respect to course-taking, the state has suffered from years of low participation in computer science from almost all students, though students of color and girls are notably absent from most of these legacy "for some" courses. Student enrollment data from historic courses, as well as the new Advanced Placement Computer Science Principles course, highlights both the overall, drastically low participation, as well as the homogenous participation in terms of student demographic groups (College 
Board, 2018). In 2017-2018, while students participated in taking over 137,000 exams nationwide, only 762 Oregon students participated in one of the two Advanced Placement Computer Science course exams. Of these Oregon students, only $10 \%$ of exam-takers were students of color, and just $23 \%$ identified as female. Statewide, only one Native American girl, one Black girl, two Native Hawaiian or Pacific Islander girls, and 12 Latina girls participated in one of the two Advanced Placement exams.

\section{Attending to the Participation Gap}

It is clear that the computer science education efforts and course offerings in Oregon to date have not been productive in broadening participation in computing in the state. With over 50 years of experimentation, significant demand from parents and persistent appeal for more computer science educated graduates from Oregon's technology industry, educators might wonder why the state failed to implement Jaquiss' vision from 1978 of "Computer Literacy for All." In part, the evidence shows that because the inclusion of computer science has historically been viewed predominantly as an opt-in offering for suburban schools, its enrichment program status has prevented the subject from becoming part of the generally available comprehensive school curriculum (Margolis et al., 2017). Further, Oregon is the only state in the United States that does not have any statewide policies that support K-12 statewide computer science education, such as continued funding, teacher certification, a state plan, state standards, allowing computer science to count for graduation requirements, or a state director that oversees computer science instruction and learning in schools (Code.org, CSTA and ECEP, 2019).

As a state, Oregon is uniquely situated for a "Computer Science for All" movement focused on implementing and sustaining computer science courses in high schools. There is a longstanding legacy of past computer science state investments and active teacher involvement in computer science education. Yet, the pressing equity gaps in computer science education in Oregon show extreme disparities in participation amongst Oregon's students that suggest a new approach for expanding computer science education is needed. For Oregon, this includes addressing not only gender, racial, and social class disparities, but also differences in opportunities to learn along the urbansuburban-rural divide.

\section{Broadening Participation in Computer Science in Oregon}

Computer Science for every student, thus, requires a more disruptive implementation approach than simply providing more opportunities for computing education as opt-in enrichment. This necessitates a shift from the historic viewing of computer science as appropriate in some schools, for a handful of students, toward a normative view of computer science as a subject for every student across the state. The thesis of this theory is that such a disruption in the implementation of computer science education is ultimately more sustainable in reaching equitable learning opportunities for students.

The "Computer Science for Oregon" program began in 2017 with goals of diversifying and expanding computer science learning opportunities for students in urban, suburban, and rural areas across the state. With support from the "Computer Science for All" program at the National Science Foundation, a major part of this initiative focuses on supporting high school teachers in developing the capacity to teach the introductory year-long Exploring Computer Science course at their schools.

The Exploring Computer Science program, with over a decade of research documenting its effectiveness in engaging diverse groups of students in learning about computing, provides a comprehensive and inquiry-based approach to introducing high school students to computer science. Along with instructional lesson plans for teachers to use, that include a comprehensive approach to computing, the Exploring Computer Science program offers an intensive, long-term professional development program. Teachers participating in the professional development program of Exploring Computer Science first attend a week-long summer Institute, then participate in quarterly learning sessions taken while teaching the course during the first year, and then participate in a second weeklong summer Institute. The second summer professional learning experience allows for teachers to reflect on their first year of teaching and continue to grow their knowledge around effective instructional practices.

The core features of the Exploring Computer Science professional development program include introducing teachers to key lessons in the curriculum, incorporating a rehearsalbased approach to learning computing concepts and pedagogy, and centering discussions about racial inequities in computer science education (Goode et al., 2014). Further, this professional development has been shown to foster a vibrant professional learning community of teachers (Ryoo et al., 2015).

To participate in the professional development program, a school's principal signs an agreement to offer the Exploring Computer Science course in the school curriculum and agrees to a school-wide commitment to recruit a wide diversity of students to the course. So far, two cohorts, and a total of 40 teachers, have begun or completed the 2-years Exploring Computer Science professional development program focused on learning introductory computer science concepts, inquirybased teaching methodologies, and strategies for teaching for equity and inclusion. In Oregon, the summer Exploring Computer Science professional development workshop takes place annually in a residential college setting in central Oregon. Subsequent quarterly professional developments are conducted during the school year, in an online setting. This is to ensure ease of participation as teachers in the program come from geographically disparate locations.

\section{THEORETICAL PERSPECTIVES OF SCHOOL REFORM TO ADDRESS EQUITY}

This study draws from school reform literature to help examine how teachers can be central to efforts for broadening participation in computing, in the context of a statewide initiative. Given that "Computer Science for All" is part of the ubiquitous democratic "for all" movement in education, 
it is useful to examine the scholarship from similar "for all" detracking efforts that have aspired to democratize access to school knowledge.

In his scholarship on education policies and the rhetoric of standards for all in England, Gillborn (2005) argues that by placing race equity at the margins of reform, educational policies retain, and extend race injustice that firmly remains at the center of the reform. Gillborn points out that systematic advantages for White students are based in a form of tacit intentionality of power-holders. He argues that white supremacy is often maintained and reproduced through the taken-forgranted privileging of white interests that often goes unexamined when creating educational policies. Thus, for efforts "for all" to be effective in reaching goals of inclusion and social justice, race equity must be considered at the center of reform strategies and goals.

Because expanding opportunities for computing education beyond enrichment and toward for all students is complex and involves changing the distribution of resources as well as changing the hearts and minds of educators, we employ Oakes' (1992) framework for understanding and changing school dynamics to promote racial, socioeconomic, and gender equity in course-taking. Oakes proposes attending to three dimensions of change that influence the social organization of schools: the technical, normative, and political elements of school reform. Further, given the empirical base highlighting the influence of teacher quality on students' opportunities to learn (Darling-Hammond, 2008), we extend Oakes' theoretical frame to highlight the empirical data suggesting the importance of a fourth dimension: pedagogy (Goode et al., 2018).

\section{Technical}

By technical, Oakes refers to the structure of curriculum differentiation-including the curriculum, systems of differentiation to determine tracks of students, and the existence of college preparation and non-college preparatory tracks at a school site. As documented in Stuck in the Shallow End (Margolis et al., 2017), course demographics are closely correlated with the relative rigor and prestige of computing courses-low-income students and students of color are often relegated to low-level computer literacy courses, while middle-class students, typically boys, represent the majority of Advanced Placement Computer Science A course-takers. This is reflected in Advanced Placement Computer Science A and Computer Science Principles exam statistics in Oregon and nationwide, which reveal that computer science has the lowest rates of female and marginalized minority participation out of all Advanced Placement STEM-related courses (Martin et al., 2015; College Board, 2018).

\section{Normative}

Addressing the normative dimension of computer science education reform includes attending to the web of cultural assumptions about what is true and "normal" and what constitutes appropriate action given these belief systems. Computer science is one of the fields most defined by stereotypes and belief systems that undercut the participation of African Americans, Latinx, Native Americans, females, and other marginalized groups. An important normative perspective in computing education is the concept of "preparatory privilege," a phenomenon in which childhood enrichment experiences and familial social capital are mistaken by educators for "innate" ability and suitability for studying more computing (Margolis et al., 2017). Students without such experiences, including lowincome students, students of color, and girls, are then labeled as not being able or suitable for even introductory computer science courses (Goode et al., 2006). Since educators, including counselors and administrators, uphold these normative belief systems at school, district, and state levels, these belief systems both influence and are influenced by policy and practice within a particular state or regional context (Hu et al., 2016).

\section{Political}

The political dimension includes how labels, status differences, and the significance of these systems are codified in schooling policies in ways that influence opportunities for academic and occupational attainment. Oakes (1992) notes the political dimension captures the ongoing struggle for individuals and groups to raise their own relative advantage in the distribution of school resources and opportunities through the development of policies that determine who receives fiscal and human resources that sustain quality effective teaching and learning. Considering the political dimension of computer science education also involves tracking which teachers are permitted to teach secondary computer science education and relatedly, how computer science counts-if it counts toward graduation or college admissions, or as a course on a Career-Technical Education pathway, and for which students (Lang et al., 2013; Kaczmarczyk et al., 2014).

\section{Inclusive Pedagogy}

Yet, equity is not frequently at the core of professional learning programs for teachers in computer science. A recent study of computer science teachers noted that only $16 \%$ of teachers consider themselves very well-prepared to incorporate students' cultural backgrounds into computer science instruction (Gordon and Heck, 2019). Building the professional capacity of teachers is essential so that all students have teachers who are able to incorporate the essential ingredients of an engaging and inclusive pedagogy in computer science courses. Darling-Hammond (2008) has indicated that teacher quality and preparation is the most important school-level influence on student learning, and that highly qualified teachers in core subject areas were inequitably distributed amongst schools. Research on computer science teacher preparation has demonstrated the importance of building the conceptual knowledge, inquiry-based pedagogy, and equitable teaching practices of computing teachers for improving learning experiences for students (Margolis et al., 2014). Further, long-term professional development programs foster the growth of dynamic professional learning communities of teachers instructing the same course, allowing for shared knowledge and in-depth discussion of teaching strategies, student work, and assessment (Ryoo et al., 2015). Peer-coaching programs have shown to be effective in its on-site model of professional support to novice computing teachers as they work toward 
developing engaging and inclusive pedagogy for all students (Margolis et al., 2015).

\section{MATERIALS AND METHODS}

The mixed method study outlined in this paper focuses on how teachers, with the support of an in-service professional development program and a "for all" attentive curriculum, can influence and drive regional and statewide computer science reform.

\section{Research Questions}

This study probes the professional learning experiences of teachers as they begin teaching a high school introductory course in computer science, and how these teachers understand their own agency and capacity in bringing computer science to their specific schools and classrooms and to diverse groups of students. Specifically, we asked:

1. How do teachers experience a residential computer science professional development program that infuses equity into the core teacher learning curriculum?

2. How do teachers understand their own agency in influencing computer science education policies and enacting educational practices that broaden participation in computing?

\section{Participants}

To address these questions, we involved 29 teacher participants attending summer Exploring Computer Science professional development in the research study examining their knowledge and agency around improving access and equity in computer science education. About half of these teachers were first-year Exploring Computer Science teachers who were preparing to teach the course for the first time the following school year, the remainder of teachers were part of the first cohort of teachers who were participating in the professional development for their second year after teaching the course for the first time at their schools. All except for one of the teacher participants noted that they had approached their school administration to seek permission to teach Exploring Computer Science and participate in professional development as part of the "Computer Science for Oregon" initiative.

\section{Data Sources}

We collected 25 pre-professional development surveys and 29 post-professional development surveys from participating teachers. Four of the teacher participants did not fill out a presurvey, but did complete the post-survey. There was no attrition of participants during the week of professional development. The reliability and validity of these survey instruments has been established with consistent and theoretically meaningful outcomes across multiple uses of these survey items with participants over the course of many years (Goode et al., 2014; Ryoo et al., 2015). Face validity has been strengthened through the central involvement of educational researchers and experts in computer science education further reviewing these survey items.

To center the first research question in this study about teacher's professional learning experiences, we report only on the items that measured teachers' growth and dispositions toward equity and inclusion that emerged through their participation in this professional learning workshop. To this end, we focus on a few individual survey items that query teachers' confidence and knowledge around equity and inclusion. Further, openended observations during the course of the week of professional development provided another source of data to triangulate research findings around teacher learning, teacher agency, and broadening participation in computing.

Over the course of the prior school year and during summer professional development, we also collected a series of interview data with eight first-year Exploring Computer Science teachers, both before and after they initially taught Exploring Computer Science. In all, the second-year Exploring Computer Science teachers noted they had taught 640 students in Exploring Computer Science during the 2018-19 school year. All but one of these teachers returned for a second year of Exploring Computer Science professional development. Our data collection focused on capturing teachers' experiences, beliefs, and attitudes about increasing access to computer science instruction in high schools. These interviews were semi-structured and lasted for 30-60 min each. For second-year Exploring Computer Science teachers, we were particularly interested in teachers' implementation of an equity-oriented course within the particular community and school context that teachers work in to capture the diversity of strategies, policies, and practices that these educators perceived to support all students in Oregon. We analyzed these interviews using thematic codes that emerged from examining the technical, political, normative, and pedagogical categories of teaching computer science in schools.

\section{Case Study Analysis}

To examine in detail the second research question that queries how teachers advocate for equity-based policies and enact equitable teaching practices to support computer science education at their schools, we compiled case studies of three of these educators. Case studies are used to present the school-site experiences of teachers as this method allows for "an empirical inquiry that investigates a contemporary phenomenon within its real-life context; when the boundaries between phenomenon and context are not clearly evident; and in which multiple sources of evidence are used" (Yin, 1984, p. 23). That is, school reform is inherently context-dependent, and understanding the interaction between structures, policies, and individual teacher and student experiences requires an examination of policies and practices as enacted in particular sociocultural communities. The data for the three case studies presented in this paper is drawn from multiple sources, including a series of interviews and surveys over the course of 13 months.

In creating case studies, we focused on more in-depth examinations of individual teachers' experiences, using data collected from three of the participants who had recently completed their first year of teaching the Exploring Computer Science course with professional development support. All of these teachers were part of the first cohort of "Computer Science for Oregon" teachers. These three teachers were selected as focal case studies based on their own personal 
and professional backgrounds and the range of geography and student demographics in the communities in which they work. We also were purposeful in our sampling to highlight areas typically overlooked in computer science education scholarship. For instance, as rural schools are often underrepresented in education policy, we include two different rural areas as cases to shed additional light on the particular needs and opportunities that might take place outside of urban and suburban schools.

\section{RESULTS}

\section{Professional Learning Community Fosters Equitable Teaching Disposition}

Our investigation into the first research question, how teachers experienced professional learning in Exploring Computer Science professional development, revealed that teachers found value in this space, specifically in terms of increasing their knowledge of content, pedagogical skills, and equitable approaches to recruiting and retaining diverse students in their introductory computer science classes. Overall, in our analysis of surveys, we found that teachers highly regarded the residential setting and community-focused approach to the professional development, with teachers noting that "collaborating with peers" was extremely valuable, and as one teacher stated, an "important activity for my learning during this week was time spent outside the classroom with other teachers, especially conversations with second-year Exploring Computer Science teachers."

In fact, though teacher isolation is often reported by the nation's computer science teachers, after a week of residential professional development, $96 \%$ of teachers reported feeling connected to the computing education community in Oregon and the Exploring Computer Science teacher group. Further, this collegial approach to teacher learning deepened teachers' own understandings of how equity, inquiry-based teaching methodologies, and computer science concepts can be interwoven. One teacher, in reporting about how she had previously struggled with the design of a lesson, reported that she had learned from a peer group of teachers about new strategies for the lesson that would support equity and student engagement, noting, "The method that this group used was really helpful to me. Actually, several lessons worked out that way this year. I got new perspectives and multiple ways to present lessons. I loved having the opportunity to work with my old cohort and the new. It was great energy and a fantastic group dynamic."

In describing their own learning and perspective around equity that emerged during the professional development workshop, teachers suggested that they already had varying degrees of familiarity with the equity issues in computer science, they grew in their thinking and skills. Upon reflection, teachers noted the following technical, normative, and pedagogical ways that their understandings of equity shifted as a result of participating in this professional development. None of the teachers addressed political dimensions in their comments about their growth in thinking about computing and equity, instead, they focused on technical, normative, and pedagogical considerations when talking about their growth. They noted:

\section{Technical Dimensions Such as Course Availability}

- Equity in computer science is a huge issue, especially at the college and professional level. I now have a more holistic view of the barriers preventing certain groups from entering the field and staying in the field. Exploring Computer Science is the class that opens the door for a lot of students that would previously be shut out. We need more comprehensive representation in computer science if the solutions for today's problems are going to be solved in a way that helps everyone and doesn't unintentionally exclude others.

- Creating supports to allow anyone to experience computer science as a potential pathway.

- Computer science at least as an introductory class must be taught to all students.

\section{Normative Dimension Such as Misperceptions and \\ Bias}

- I believe teachers have to be more active and promote this class as one for ALL students. Many students will miss out if they feel they are not qualified. Too many opportunities are missed by students to take computer science due to a misunderstanding of the curriculum and preconceived racial/gender biases.

- I feel more strongly than ever that computer science needs to change and become more diverse. This professional development reinforces my commitment.

\section{Pedagogical Dimension}

- This training provided some great insight on improving my practice with equity and inquiry.

- I now know that it is possible to create a curriculum that is taught through exposing kids to culture.

- I have a better understanding of what equity looks like as far as classroom instruction and student participation

- It is something that needs to be monitored and thought about each lesson.

Importantly, several teachers noted that while their perspectives haven't shifted because "they were already there" in terms of their consideration of equity, a few noted that they came up with "new ways to buck the trend" and collected new tools to back up their equity thinking and practices. One teacher, as part of the first cohort who was experiencing their second summer in Exploring Computer Science professional development, reflected that the first professional development had the most impact, stating, "Not much change in thinking this year, but I had a huge shift in perspective last year." Yet, most second-year teachers reported how their knowledge and agency around addressing equity issues in their own professional practice had deepened, including their repertoire of inclusive recruitment strategies and pedagogical practices.

Descriptive quantitative measures also demonstrate overall increases in how participating teachers reported their own confidence in their pedagogical knowledge, curricular knowledge, and equitable practices for teaching the course as a result of participating in Exploring Computer Science 
TABLE 1 | Teachers' confidence as reported in pre- and post-professional development surveys.

\begin{tabular}{lccc}
\hline Confidence & $\begin{array}{c}\text { Using } \\
\text { inquiry- } \\
\text { based } \\
\text { strategies }\end{array}$ & $\begin{array}{c}\text { Teaching } \\
\text { computer } \\
\text { science } \\
\text { concepts }\end{array}$ & $\begin{array}{c}\text { Using equitable } \\
\text { practices to } \\
\text { support student } \\
\text { learning }\end{array}$ \\
\hline $\begin{array}{l}\text { Pre-professional } \\
\text { development confident } \\
\text { or very confident }\end{array}$ & $79 \%$ & $55 \%$ & $66 \%$ \\
$\begin{array}{l}\text { Post-professional } \\
\text { development confident } \\
\text { or very confident }\end{array}$ & $90 \%$ & $76 \%$ & $79 \%$ \\
\hline
\end{tabular}

professional development. Table 1 compares the rates of participants who noted they felt "confident" or "very confident" in using inquiry-based teaching strategies, teaching computing concepts, and using equitable practices to support student learning. As Table 1 demonstrates, post-professional development reports showed dramatically higher rates of confidence across these three focal areas. Of course, these results might be expected after an intensive learning experience, though when interpreted alongside observations and interview data, these survey results reinforce that teachers reported growth in all three areas of focus, including equity.

\section{Case Studies}

To study the second research question about teacher agency and enactment of equitable policies and practices, we offer three cases studies of teachers situated in their own school contexts. In each of these cases, we detail how teachers understand their own agency in influencing computer science education policies and inclusive educational practices that impact their own classrooms, especially in terms of broadening participation in computing.

\section{Riverway High School}

Carol has been a teacher at Riverway for 10 years. She holds endorsements in science, general science, biology and intermediate mathematics. Last year, she taught one section of Exploring Computer Science, three sections of science, and one section of a college-preparatory advising course, AVID. Riverway, a high school of under a thousand students, is the most diverse school in the state of Oregon, and an AVID Site of Distinction. Carol explains that most of the students at Riverway "are coming from poverty, they would be first-generation postsecondary students, especially graduating from post-secondary, most parents have low levels of education." Sixty-nine percent of the school's students are from minoritized groups, 45 percent are students of color. Many students are recent immigrants or are children of immigrants. The student body represents over one hundred nationalities, whose flags are proudly on display in the school cafeteria. The school supports a significant number of English Language Learners. Carol describes her teaching style as student-centered. To her it is more important to focus on how she will teach, rather than what she will teach. She focuses on high engagement best practices, collaboration, hands-on, movement, games-loading "creative fun." She spends a lot of time establishing relationships with students.

Carol is a steadfast advocate for the students at Riverview, especially urging the need and importance of introductory computer science courses. She explains: “... as a teacher in a diverse school, I have this [...] understanding of the opportunities for the careers that are available for kids. And right now, the computer industry is expanding at a rate that is unbelievable. And there are jobs, really good, high paying jobs ... if they can build the skills in order to attain them." She further states, "I want people to know that they [the students at Riverview] are all really excited about learning and they are all really excited about their future. ... so, our kids, they have dreams and they have goals, and they want to get there, they just, a lot of them, they don't have that knowledge, and their family know how." She adds, "we need to make sure that we are providing real opportunities to learn computer science, especially in underfunded schools and [...] our kids are ready and they are worth it and they deserve the opportunity." Carol devotes a great deal of her time to encouraging and supporting individual students, ensuring that they succeed in her Exploring Computer Science class.

In the 2018-19 academic year, Riverway introduced Exploring Computer Science as an alternative to a required physical science course. The course fulfilled a science requirement option for freshman. This came as a mandate from the school district's upper administration. As the school's Science faculty was not given an opportunity to weigh in, the rollout of Exploring Computer Science as a physical science alternative was contentious. Because it fulfilled a school requirement, three sections of the course were offered. It saw participation from demographics closely resembling that of the school. Carol reports that the equity-focused pedagogical strategies for teaching computer science she was introduced to during the Exploring Computer Science professional development kept students highly engaged and they enjoyed the class. She was able to see that with an appropriate curriculum and intentional pedagogy all students could be successful in an introductory computer science course.

Despite having a high level of student engagement and being a good fit for the high school district's commitment to equity, Exploring Computer Science has been reclassified as one option for receiving science credit, though not required, for the following academic year. Carol reports that due to it being an elective, the class was poorly advertised and drew smaller enrollment numbers. Although the school saw an increase in Advanced Placement computer science enrollment, which Carol attributes to a successful launch of Exploring Computer Science, the course offerings have been reduced to two smaller sections, diminishing the "for all" momentum built during the prior year. Riverway is an example of political barriers to implementing "Computer Science for All." Even though the school district's administration embraced the "for all" tenet for computer science education, there was a lack of buy-in from the science department faculty, who were impacted by the top-down mandate to count Exploring Computer Science as a science credit alternative. As identified in Priestley et al. (2012), this teacher's efforts were constrained by the "temporal, material, and social context" 
created by administrative decisions. When teachers are not empowered to collaborate on situating computer science in a school, the sustainability of well-meaning efforts and hardearned successes are jeopardized.

\section{Villa High School}

Maye has been teaching computer science for over a decade. She immigrated to the United States from the Middle East, where she had earned a Master's degree in computer science. After immigrating, she considered working in the technology industry, but decided to instead focus on raising her children. She entered the teaching profession once her children were older and began her career as a Math teacher. Villa High School, where Maye teaches, is located in a town of 55,000 residents. The school serves about 2,300 students: 30\% Latinx, 1\% Black, $60 \%$ qualify for free and reduced lunch, and many students are English Learners. Maye took over computer science classes at Villa from another teacher and immediately fell in love. The classes which she inherited exclusively focused on programming and game development.

Maye quickly noticed that the students who enrolled in her computer science classes were mostly white boys. She decided to focus on shifting the demographics. To this end, she started introducing computer science to middle school students during Villa's Summer STEM camps, intended to introduce students to high school offerings. She targeted a camp that focused on girls and another that focused on children of migrant workers. Maye developed a 1-day computer science introduction which she states was meant to address misconceptions about the subject being just game programming. She also searched out and adapted an introduction to computer science curriculum. She chose Exploring Computer Science because of its equity and inclusive pedagogy focus. She saw a shift in demographics of students taking the introduction to computer science course but there was also high attrition. She is currently working on a multiple-day introduction that will do 1 day of art, 1 day of storytelling and animation, and 2 days of programming games. Maye is passionate about the need to offer computer science to all students. She states: "because it's problem-solving skills, it's literacy, it's reading and writing and attention to detail [...] computer science is not just programming, it is in every aspect of life."

Over the past several years Maye has developed a computer science Career-Technical Education pathway at Villa which covers introduction to computer science (Exploring Computer Science), programming in Visual Basic, advanced programming in $\mathrm{C}++$, dual-enrollment computer programming courses (students are able to earn high school and Community College credit at the same time), and Advanced Placement Computer Science Principles. Maye reports that students can take computer science even if they are not in the pathway, but most don't. The computer science classes count toward the school's certificate of Career-Technical Education pathway completion or can count as electives. Maye is deeply involved in the leadership of state's Computer Science Teachers Association. She works tirelessly on changing the misconception about computer science. She feels that many students don't really understand what they are going to learn when they sign up for the introduction to computer science class. They think they will just be making video games. They are surprised that there is math, problem-solving, collaboration, writing, doing things with pen and paper and not necessarily on a computer. She has been speaking with other teachers, counselors and administrators to address their misconceptions about the course so that they are able to prepare students for what they will be experiencing in the class.

Maye strongly believes that all students can succeed in a computer science course if they have a clear understanding of the nature of the course and are well-supported. However, she is the only teacher at Villa who teaches computer science. Students who are considering the computer science CareerTechnical Education are choosing between fifteen CareerTechnical Education pathway offerings. Although Maye supports the computer science for all effort, at Villa, only a small number of students have the opportunity to take computer science. This is an example of the technical and normative dimension of computer science education. As pointed to in Lasky (2005), here, teacher agency is constrained by structural policies of the school. Because at Villa computer science is relegated to a career track, it is predominantly available to students who either self-select the track or are recruited based on beliefs about who can and should do computer science. Rather than providing computer science education for all, Villa remains a school that maintains the normative view that computer science is for some.

\section{Cornerstone High School}

Luis began his teaching career in Mexico City, Mexico. He came to teach by invitation from a friend. He was studying for a bachelor's degree in architecture, when a friend who was teaching at a private school in Mexico City asked if he would like to teach. Luis replied that he didn't have any teaching experience, but the friend told him that the school would support him, and he started teaching in a middle school. His first class was computers. He later graduated with a bachelor's degree in Architectural Engineering and a minor in teaching. In the US, his degree from Mexico transferred and he has been teaching math and science. In Mexico, before coming to the US, he was teaching at a high school. He taught in the occupational track, classes focused on architectural engineering and construction. He also taught art classes at the university. During the 2018-19 academic year, Luis and another teacher at Cornerstone each taught a section of Exploring Computer Science for the first time. The course will be offered again next year and both teachers are excited to continue teaching computer science at the school.

Cornerstone High School, where Luis teaches Math, Science, AVID and Exploring Computer Science, is a Spanish-English bilingual public charter school. It is located in a rural town, with about 11,000 residents. The school has a history with the local Latinx community and has a large population of Latinx students. It is a K-12 school and most students have been at the school from an early age. Luis reports that the students at this school have been working at becoming bilingual since elementary school. "Part of the motivation of our principal is to create a culture ... a bilingual culture." There are 64 students in the high school. According to Luis, it is important for students to learn computer science because it is everywhere. In his case, he thinks 
that learning computer science opened doors for him and has helped him not only in his career but also in his daily life. Luis sees it as a subject that can open doors for students as it did for him. He states, "[i]f we are trying to help our students to overcome from that economic situation that they are living with, it could open some doors for them ... they could be ready for college." Additionally, he is aware that there are people out there who would enjoy knowing the behind the scenes of computers, how they work, who would not normally have the opportunity to, and "since that's what our school is all about ... we got a lot of girls, high Latinx population, and these are traditionally underserved in the computer industry, why not introduce them and see if this is a thing they would love."

Cornerstone is an example of a sustainable computer science for all approach. Both Luis and his colleague individually approached the school principal and advocated for the need to have an introductory computer science course at the school. His colleague had previously done Hour of Code activities at the high school but they both believed that they needed a more sustained course. Luis also felt that the school needed an engaging and supportive introductory course. Their principal contacted the Oregon Department of Education about available curriculum and was told about the Exploring Computer Science Professional Development program, which focused on supporting Oregon teachers. Luis and the colleague attended the professional development and report that the equity and inclusive strategies they learned helped them provide an introductory experience that resulted in a high level of engagement and success.

The Exploring Computer Science class at Cornerstone is required for all students. Even though some students struggled or took some time to get engaged, Luis reports that they had to keep trying, and were incentivized to complete assignments in order to earn credit and fulfill the requirement. Because there is buy-in about "Computer Science for All" from administration and teachers, both Exploring Computer Science teachers at Cornerstone could focus on using inclusive pedagogy strategies to support their students and shift the normative beliefs of who can do computer science. In this case, teacher agency is best contextualized as in Biesta and Tedder (2007), an alignment between teachers' intentions/actions, school environment, and administration. The momentum at the school is strong enough that Luis's colleague has started looking into adding Advanced Placement Computer Science Principles course as the follow-up course to Exploring Computer Science.

\section{DISCUSSION}

These case studies elucidate the key problems of practice and opportunities for critical hope that teachers hold as they teach "Computer Science for All." Though their contexts vary in terms of geography, identity, and student demographics, these teachers collectively shed light on the lived practices of democratizing computer science education. With the curricular, pedagogical, and policy support of the "Computer Science for Oregon" initiative, the teacher professional learning results, alongside the
TABLE 2 | Developing equity-focused practices for computer science school reform.

\begin{tabular}{|c|c|}
\hline $\begin{array}{l}\text { Dimensions of } \\
\text { school reform } \\
\text { for equity }\end{array}$ & $\begin{array}{l}\text { Supportive policies and practices that supports equity } \\
\text { and teacher agency in statewide computer science }\end{array}$ \\
\hline Technical & $\begin{array}{l}\text { - Adoption of introductory computer science course } \\
\text { incorporated into school schedule } \\
\text { - A common curriculum supports teacher collaboration and } \\
\text { can assess inclusive student learning } \\
\text { - Culturally responsive curricular material supports student } \\
\text { learning, especially for historically underrepresented groups } \\
\text { - Course coded to be available to students across } \\
\text { academic "tracks" }\end{array}$ \\
\hline Pedagogical & $\begin{array}{l}\text { - Professional development that supports inquiry- and } \\
\text { equity-oriented instruction } \\
\text { - Collaboration with other teachers teaching the same course } \\
\text { at the same school } \\
\text { - Collaboration with other teachers outside of school, } \\
\text { including other "Computer Science for All" teachers, } \\
\text { educators part of Computer Science Teachers Association } \\
\text { state network }\end{array}$ \\
\hline Political & $\begin{array}{l}\text { - Computer science courses counts toward a graduation } \\
\text { requirement } \\
\text { - Teacher support for offering introductory and inclusive } \\
\text { computer science courses } \\
\text { - School-level counselor and teacher faculty support from } \\
\text { other disciplines/programs } \\
\text { - Top-down support from school leadership, including } \\
\text { principals } \\
\text { - Top-down support from school district leadership, } \\
\text { including superintendents and school boards }\end{array}$ \\
\hline Normative & $\begin{array}{l}\text { - Educator beliefs about suitability of computer science } \\
\text { course for all students } \\
\text { - Opportunity to study computer science designed to be } \\
\text { available and equitable for all students as part of general } \\
\text { education track } \\
\text { - Sufficient number of teachers assigned by school to } \\
\text { support computer science courses for all students at } \\
\text { high school }\end{array}$ \\
\hline
\end{tabular}

case studies, detail the multiple factors that must be considered and attended to in efforts to democratize computer science.

Drawing from these findings and connecting the narratives of teachers with the theoretical framework on equity-oriented school reform, we have compiled the following set of practices that support a social justice approach to broadening participation in secondary computer science (Table 2). To supplement and apply a racially- and gender-conscious approach to broadening participation in computing, we categorize these findings in terms of the technical, normative, political, and pedagogical dimensions that have been found to support computer science for all students.

The descriptions of teacher agency, in terms of possibilities and constraints, also indicate that policy and teacher education efforts, when connected in meaningful ways, can help sustain the availability of computer science courses and necessary educational resources. With an equity-focused professional development program, we witnessed how teachers can enact agency within their particular educational environment to influence regional and statewide reform efforts to broaden 
participation in computing education. The results from this study also highlight that equity must remain at the core of state-wide reform effort, or else efforts will likely raise opportunities for the same overrepresented groups.

The interplay between structures and individual beliefs also suggest that to ensure that computer science education will take hold, and be sustainable, for all students, schools must simultaneously attend to the technical, pedagogical, political, and normative dimensions of "Computer Science for All" efforts. While professional development sessions and statewide initiatives can support the introduction of inclusive and evidence-based curriculum and support professional learning for teachers, attending to the political climate and normative notions of who belongs in computer science is a key strategy for nurturing school-level buy-in for computer science being placed in the core curriculum. These findings underscore that before scaling statewide reform efforts in computing, we must attend to the policies, practices, and belief systems in schools to ensure reform efforts do not just increase the numbers of students enrolling in computing classes, but actually broaden the engagement and participation rates of historically minoritized students.

Finally, we cannot overstate the importance of teachers as social change agents in expanding normative notions about who belongs in computer science classes in twenty-first century high schools. Overwhelmingly, the case studies showcase the tremendous advocacy efforts of computer science teachers in serving as change agents diversifying and democratizing Oregon high school computer science education. The teachers in this study exemplified how broadening participation in computing requires a committed network of educators who enact social justice principles both within their schools and classrooms, and as part of the large computer science teacher community.

\section{CONCLUSION}

The research presented in this paper documents how a statewide initiative aiming to provide more equitable access and participation in high school computer science courses supported teacher learning and was generative for school-level

\section{REFERENCES}

Apple, M. W. (1978). Ideology, reproduction, and educational reform. Comp. Educ. Rev. 22, 367-387. doi: 10.1086/445993

Ashcraft, C., Eger, E. K., and Scott, K. A. (2017). Becoming technosocial change agents: intersectionality and culturally responsive pedagogies as vital resources for increasing girls' participation in computing. Anthropol. Educ. Q. 48, 233-251. doi: 10.1111/aeq.12197

Bennett, J., Hobbs, M., Lott, J., Piccolino, A., Wheeler, M., and Whitman, N. (1980). New programs. Math. Teach. 73, 544-546. Available online at: www.jstor.org/ stable/27962313 (accessed July 10, 2019).

Biesta, G., and Tedder, M. (2007). Agency and learning in the lifecourse: towards an ecological perspective. Stud. Educ. Adults 39, 132-149. doi: 10.1080/02660830.2007.11661545

Code.org, CSTA and ECEP. (2019). 2019 State of Computer Science Education. Retrieved from: https://advocacy.code.org/2019_state_of_cs.pdf (accessed September 13, 2019). reform. Though the professional learning for teachers showed a positive impact in preparing teachers to teach computer science and address local policy with equity principles, we discovered key barriers and opportunities at school, district, regional, and state levels impeded and propelled initial efforts for enacting teacher agency at reaching "Computer Science for All" in schools. Still, incremental progress has increased learning opportunities for hundreds of Oregon students. The knowledge gained from this study of state computer science implementation can inform the efforts of other states seeking to identify wholeschool support strategies to broaden participation in high school computing.

\section{DATA AVAILABILITY STATEMENT}

The datasets generated for this study will not be made publicly available due to confidentiality concerns for participants.

\section{ETHICS STATEMENT}

This study involved human participants was reviewed and approved by the University of Oregon Research Compliance Services. The participants provided informed consent to participate in this study.

\section{AUTHOR CONTRIBUTIONS}

JG and MS led efforts in data collection and analysis. JHu and JHo contributed to the program design and implementation. All authors were involved in the writing of this paper.

\section{FUNDING}

This material was based upon work supported by the National Science Foundation under Grant No. CNS-1738883. Any opinions, findings, and conclusions or recommendations expressed in this material are those of the authors and do not necessarily reflect the views of the National Science Foundation.

College Board (2018). AP Program Participation and Performance Data 2018. Retrieved from: https://research.collegeboard.org/programs/ap/data/ participation/ap-2018 (accessed July 15, 2019).

Darling-Hammond, L. (2008). Teacher learning that supports student learning. Teach. Intell. 2, 91-100.

Darling-Hammond, L., and Berry, B. (2006). Highly qualified teachers for all. Educ. Leadersh. 64:14.

Gillborn, D. (2005). Education policy as an act of white supremacy: whiteness, critical race theory and education reform. J. Educ. Policy 20, 485-505. doi: $10.1080 / 02680930500132346$

Goode, J. (2008). "Increasing diversity in K-12 computer science: strategies from the field," in Proceedings of the 39th SIGCSE Technical Symposium on Computer Science Education, Vol. 40 (Portland, OR), 362-366.

Goode, J., Estrella, R., and Margolis, J. (2006). "Lost in translation: gender and high school computer science," in Women and Information Technology: Research on Underrepresentation, eds J. M. Cohoon and W. Aspray (Cambridge, MA: MIT Press). doi: 10.7551/mitpress/9780262033459.003.0003 
Goode, J., Flapan, J., and Margolis, J. (2018). "Computer science for all: a school reform framework for broadening participation in computer science," in Diversifying Digital Learning: Online Literacy and Educational Opportunity, eds W. Tierney, Z. Corwin, and A. Ochsner (Baltimore, MA: Johns Hopkins Press), 45-65.

Goode, J., Margolis, J., and Chapman, G. (2014). "Curriculum is not enough: the educational theory and research foundation of the exploring computer science professional development model," in Proceedings of the 45th ACM Technical Symposium on Computer Science Education (Atlanta, GA: ACM), 493-498. doi: $10.1145 / 2538862.2538948$

Gordon, E. M., and Heck, D. J. (2019). 2018 NSSME+: Status of High School Computer Science. Chapel Hill, NC: Horizon Research, Inc.

$\mathrm{Hu}$, H. H., Heiner, C., and McCarthy, J. (2016). "Deploying exploring computer science statewide," in Proceedings of the 47th ACM Technical Symposium on Computing Science Education (Memphis, TN: ACM), 72-77. doi: $10.1145 / 2839509.2844622$

Kaczmarczyk, L., Dopplick, R., and and, E. P., Committee (2014). Rebooting the Pathway to Success: Preparing Students for Computing Workforce Needs in the United States. Education Policy Committee, Association for Computing Machinery (New York, NY: ACM).

Ladson-Billings, G. (1995). But that's just good teaching! The case for culturally relevant pedagogy. Theory Pract. 34, 159-165. doi: 10.1080/00405849509543675

Lang, K., Galanos, R., Goode, J., Seehorn, D., Trees, F., Phillips, P., et al. (2013). Bugs in the System: Computer Science Teacher Certification in the US. A report by The Computer Science Teachers Association and The Association for Computing Machinery. Available online at: http://csta.acm. org/ComputerScienceTeacherCertification/sub/CSTA_BugsInTheSystem.pdf (accessed April 13, 2014).

Lasky, S. (2005). A sociocultural approach to understanding teacher identity, agency and professional vulnerability in a context of secondary school reform. Teach. Teach. Educ. 21, 899-916. doi: 10.1016/j.tate.2005.06.003

Lee, V. E., Croninger, R. G., and Smith, J. B. (1997). Course-taking, equity, and mathematics learning: testing the constrained curriculum hypothesis in US secondary schools. Educ. Eval. Policy Anal. 19, 99-121. doi: 10.3102/01623737019002099

Margolis, J., Estrella, R., Goode, J., Holme, J., and Nao, K. (2017). Stuck in the Shallow End: Education, Race, and Computing, Revised Edn. Cambridge, MA: MIT Press.

Margolis, J., Goode, J., Chapman, G., and Ryoo, J. J. (2014). That classroom 'magic'. Commun. ACM 57, 31-33. doi: 10.1145/2618107
Margolis, J., Goode, J., and Ryoo, J. J. (2015). Democratizing computer science. Educ. Leadersh. 72, 48-53.

Martin, A., McAlear, F., and Scott, A. (2015). Path Not Found: Disparities in Access to Computer Science Courses in California High Schools. Available online at: https://eric.ed.gov/?id=ED561181 (accessed August 2, 2019).

Oakes, J. (1992). Can tracking research inform practice? Technical, normative, and political considerations. Educ. Res. 21, 12-21. doi: 10.3102/0013189X021004012

Priestley, M., Edwards, R., Priestley, A., and Miller, K. (2012). Teacher agency in curriculum making: agents of change and spaces for manoeuvre. Curriculum Inq. 42, 191-214. doi: 10.1111/j.1467-873X.2012. 00588.x

Ryoo, J., Goode, J., and Margolis, J. (2015). It takes a village: supporting inquiry-and equity-oriented computer science pedagogy through a professional learning community. Comp. Sci. Educ. 25, 351-370. doi: 10.1080/08993408.2015.1130952

Scott, A., Koshy, S., Rao, M., Hinton, L., Flapan, J., Martin, A., et al. (2019). Computer Science in California's Schools: An Analysis of Access, Enrollment, and Equity. Retrieved from: https://www.kaporcenter.org/wp-content/uploads/ 2019/06/Computer-Science-in-California-Schools.pdf (accessed July 15, 2019).

U.S. Equal Employment Opportunity Commission (2016). Diversity in HighTech. Retrieved from: https://www.eeoc.gov/eeoc/statistics/reports/hightech/ (accessed August 2, 2019).

Yin, R. (1984). Case Study Research: Design and Methods. Beverly Hills, CA: Sage Publications.

Zweban, S., and Bizot, B. (2018). 2018 Tualbee Survey. Computer Research Association. Retrieved from: https://cra.org/wp-content/uploads/2019/05/ 2018_Taulbee_Survey.pdf (accessed July 15, 2019).

Conflict of Interest: The authors declare that the research was conducted in the absence of any commercial or financial relationships that could be construed as a potential conflict of interest.

Copyright (c) 2020 Goode, Skorodinsky, Hubbard and Hook. This is an open-access article distributed under the terms of the Creative Commons Attribution License (CC $B Y)$. The use, distribution or reproduction in other forums is permitted, provided the original author(s) and the copyright owner(s) are credited and that the original publication in this journal is cited, in accordance with accepted academic practice. No use, distribution or reproduction is permitted which does not comply with these terms. 